\title{
Accuracy of cardiac output estimations by transthoracic echocardiography compared with an accepted method of thermodilution, the pulmonary artery catheter, in the critically ill patients
}

\author{
J Leache Irigoyen*, J Marín Corral, I Oliva Zelaya, G Moreno Muñoz, V Blázquez Alcaide, M Bodí Saera, \\ C Villavicencio Lujan
}

From ESICM LIVES 2015

Berlin, Germany. 3-7 October 2015

\section{Objectives}

To evaluate the accuracy of cardiac output (CO) measurements by intensive care unit (ICU) physicians performing transthoracic echocardiography with pulsed-wave doppler ultrasound (PWD), compared with the pulmonary artery catheter (PAC).

\begin{abstract}
Methods
Prospective observational cohort study. A total of 42 consecutive critically ill patients who required hemodynamic monitoring with pulmonary artery catheter were enrolled over a period of 18 months. Demographic data, reason for admission, comorbidities, APACHE II, SOFA, need for vasoactive drugs and acceptability of the ultrasound measurements, were analyzed. In each patient, three PWD-CO estimations were obtained by three different observers with basic echocardiography training. The PWD-CO was obtained using the maximum of three left ventricular outflow tract (LVOT) diameter measurements and the mean of three LVOT velocity time integral measurements. The PAC-CO was obtained averaging the results of 3 thermodilutions. The mean of the three PWD-CO estimations and the PAC-CO were compared to evaluate the agreement between the two methods. Patients with no regular sinus rhythm, aortic valve disease or with impossibility to perform the echocardiographic measurements were excluded. The interobserver accuracy and the agreement between both methods were measured by the coefficient
\end{abstract}

Joan XXIII Tarragona University Hospital, Intensive Care Medicine, Tarragona, Spain

(C) 2015 Leache Irigoyen et al.; This is an Open Access article distributed under the terms of the Creative Commons Attribution License (http://creativecommons.org/licenses/by/4.0), which permits unrestricted use, distribution, and reproduction in any medium, provided the original work is properly cited. of intraclass correlation (CIC) and a Bland-Altman plotting (BAP).

\section{Results}

From a total of 42 studied patients, 22 were excluded. In 14 patients $(33 \%)$ it was impossible to perform the echocardiographic measurements. The average age was 67 years, $79 \%$ male. The average of the APACHE II and SOFA scores were 23 ( \pm DE 8.41) and 7 ( \pm DE 2.86). The most frequent diagnosis on admission to the ICU was septic shock (43\%) and the majority of patients required mechanical ventilation $(83 \%)$ and vasoactive drugs (79\%). The interobserver agreement was considered good according to the CIC 0.7 (IC 95\% 0.48-0.86; $\mathrm{p}<0.001)$. The BAP demonstrated acceptable agreement with a mean of differences 0.64 litres/minute, standard deviation of 1.18 litres/minute and 95\% limits of agreement of -1.73 to 3.01 litres/minute. When The CO was

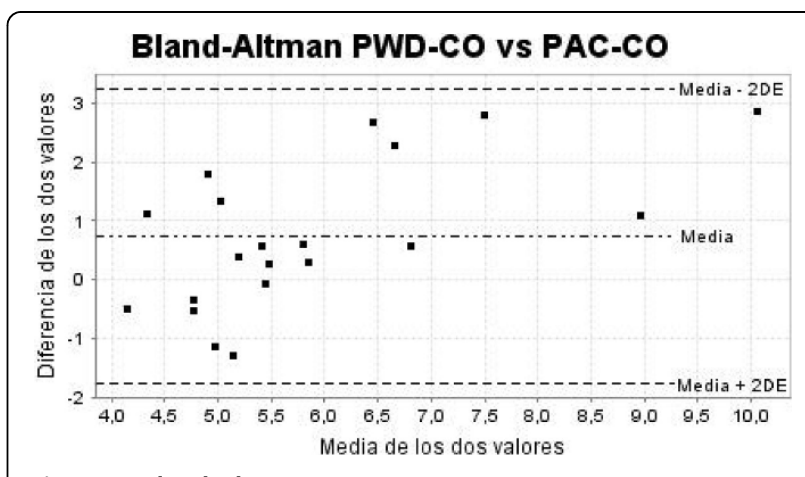

Figure 1 Bland-Altman PWD-CO vs PAC-CO. 


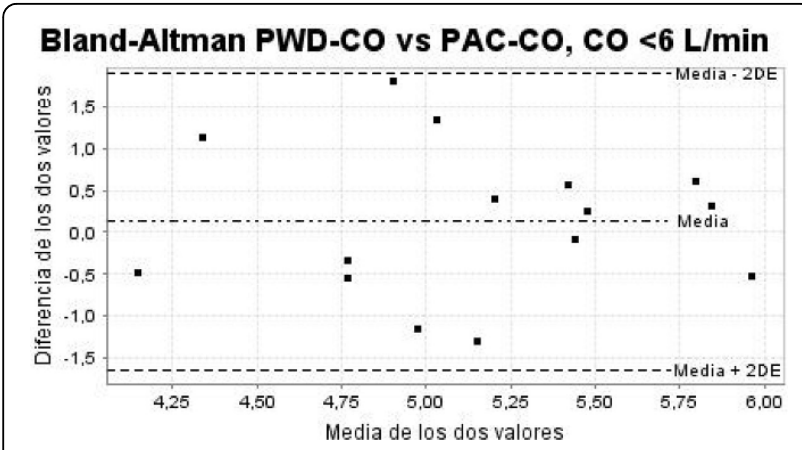

Figure 2 Bland-Altman PWD-CO vs PAC-CO, CO $<6$ L/min.

lower than 6 litres/minute, the agreement improved, with a mean of differences 0.13 litres/minute, standard deviation of 0.89 litres/minute and $95 \%$ limits of agreement of -1.64 to 1.90 litres/minute.

\section{Conclusions}

In critically ill patients with adequate echocardiographic images, the PWD-CO estimation can be reproducible between observers with basic echocardiographic training and showed acceptable agreement with PAC-CO. In the group of patients with $\mathrm{CO}$ less than 6litres/minute the agreement is even better, demonstrating the PWD-CO estimation reliable and useful in this group of patients.

Published: 1 October 2015

\section{Reference}

1. McLean AS, Needham A, Stewart D, Parkins R: Estimation of cardiacoutput by non-invasive echocardiographic techniques in the critically illsubject. Anaesth Intensive Care 1997, 25(3):250-254.

doi:10.1186/2197-425X-3-S1-A598

Cite this article as: Leache Irigoyen et al: Accuracy of cardiac output estimations by transthoracic echocardiography compared with an accepted method of thermodilution, the pulmonary artery catheter, in the critically ill patients. Intensive Care Medicine Experimental 2015 3(Suppl 1): A598.

\section{Submit your manuscript to a SpringerOpen ${ }^{\mathcal{O}}$ journal and benefit from:}

- Convenient online submission

- Rigorous peer review

- Immediate publication on acceptance

- Open access: articles freely available online

- High visibility within the field

- Retaining the copyright to your article 